\title{
A influência da composição química e da finura no desempenho de cimentos álcali ativados obtidos com escórias de alto forno
}

\author{
The influence of chemical composition and \\ fineness on the performance of alkali \\ activated cements obtained from \\ blast furnace slags
}

Eloise Aparecida Langaro ${ }^{1}$, Caroline Angulski da Luz ${ }^{2}$, Islas Stein Buth ${ }^{2}$, Maryah Costa de Moraes ${ }^{2}$, José Ilo Pereira Filho ${ }^{2}$, Adalberto Matoski ${ }^{1}$

\footnotetext{
${ }^{1}$ Universidade Tecnológica Federal do Paraná, Campus Curitiba. e-mail: elolangaro@hotmail.com; adalberto@utfpr.edu.br

${ }^{2}$ Universidade Tecnológica Federal do Paraná, Campus Pato Branco.

e-mail: angulski@utfpr.edu.br; islas_sb@hotmail.com; maryah_moraes@hotmail.com; ilofilho@yahoo.com.br
}

\begin{abstract}
RESUMO
A busca por aglomerantes de menor impacto ambiental, relacionado principalmente à emissão de $\mathrm{CO}_{2}$, tem crescido na última década, em especial, por aqueles isentos de clínquer. Cimentos álcali ativados (CAT's) são obtidos através da mistura de materiais sílico-cálcico-aluminosos com um ativador alcalino e, portanto, podem reduzir em até $80 \%$ a emissão de $\mathrm{CO}_{2}$ quando comparados com o Cimento Portland (CP). Pesquisas recentes têm mostrado que CAT's podem apresentar propriedades físicas e mecânicas equivalentes ou superiores àquelas apresentadas pelo $\mathrm{CP}$, entretanto, a ativação da matéria prima é complexa, pois depende das suas características. Trabalhos recentes têm mostrado a forte influência das características da matéria-prima no desempenho do CAT, porém, pouco mencionada na literatura. Assim, este estudo teve como objetivo avaliar a influência das características da escória de alto forno, finura e composição química, no comportamento dos CAT's, visando contribuir no entendimento dos seus mecanismos de hidratação. Para tanto, foram empregadas duas escórias, A e B, as quais foram submetidas a diferentes tempos de moagem e, ativadas com $5 \%$ de $\mathrm{NaOH}$. Foram confeccionadas argamassas e pastas para testes de resistência à compressão ( 7 e 28 dias), monitoramento do calor de hidratação e investigação da microestrutura (DRX e DSC). Os resultados mostraram que as argamassas confeccionadas com escória A obtiveram ótimo desempenho mecânico, com valores próximos a $48 \mathrm{MPa}$ aos 28 dias, bastante superior à escória $\mathrm{B}$, independente da finura e com maior formação de CSH. A hipótese provável desse estudo é que o sistema formado no CAT com escória A, por apresentar maior teor de $\mathrm{Al}_{2} \mathrm{O}_{3}$, poderia propiciar a formação de $\mathrm{CSH}$ com maior incorporação de $\mathrm{Al}$ e menor cristalinidade, contribuindo na resistência mecânica.
\end{abstract}

Palavras-chave: Cimento álcali ativado, escória de alto forno, composição química, finura.

\section{ABSTRACT}

New binders are being developed for concrete in order to reduce the environmental impact mainly related to $\mathrm{CO}_{2}$ emissions. Alkali -activated cements (CATs) are obtained from lime-aluminosilicate materials and an alkali activator and can reduce by $80 \%$ the emission of $\mathrm{CO}_{2}$ compared to Portland Cement (PC). Papers have also shown physical and mechanical properties similar or higher than those presented by the PC, however, the activation of raw material is complex. Recent papers have also have showed a strong influence of the characteristics of raw material on the performance of CAT, however, little mentioned in the literature.. Therefore, this paper aimed to analyze the influence of characteristics of blast furnace slag (fineness and chemical composition) on the behavior of activated alkali cements. For this purpose, two slags were used, A and $\mathrm{B}$, which were submitted to different milling times; and activated using $5 \%$ of $\mathrm{NaOH}$. Mortars and pastes were prepared for compressive strength testing ( 7 and 28 days), measurements of heat of hydration and in- 
vestigation of microstructure (XRD and DSC) were made. The results showed that the mortar made with slag A reached a very good mechanical performance, close to $48 \mathrm{MPa}$ at 28 days, and higher formation of $\mathrm{CSH}$, in opposite of slag B. The probable hypothesis of this study is that the system formed in CAT made with slag A (containing more $\mathrm{Al}_{2} \mathrm{O}_{3}$ ) could provide $\mathrm{CSH}$ with a greater incorporation of $\mathrm{Al}$ and a lower crystallinity, increasing the mechanical strength.

Keywords: Alkali activated cement, blast furnace slag, chemical composition, fineness.

\section{INTRODUÇÃO}

A produção de cimentos Portland é bastante agressiva ao meio ambiente, pois consome grande quantidade de calcário, de energia, para queima e trituração do clínquer e, principalmente, gera grandes quantidades de gás carbônico. Nos últimos anos, as cimenteiras vêm sofrendo pressões devido ao grande impacto ambiental envolvido nos processos de fabricação, em especial, a questão relacionada à geração de $\mathrm{CO}_{2}$.

Estima-se que aproximadamente $90 \%$ do dióxido de carbono gerado na fabricação do cimento Portland (CP) ocorrem durante a produção do clínquer [1] e que, para cada tonelada de CP produzida, é extraída 1,15 tonelada de calcário e despejada na atmosfera 1tonelada de $\mathrm{CO}_{2}[2]$.

Com o objetivo de reduzir essas emissões e aumentar a disponibilidade de matéria-prima, pesquisas têm-se direcionado a estudar aglomerantes isentos de clínquer, como é o caso dos cimentos álcali ativados (CAT's).

CAT's são produzidos pela mistura de produtos compostos por alumina, óxidos de cálcio e silicatos, como a cinza volante, escória de alto forno, metacaulim, e por uma solução alcalina ativadora, normalmente hidróxidos metálicos, carbonatos ou silicatos (water glass) [3].

Em função, principalmente, da composição química da matéria-prima ativada, o CAT pode apresentar características e propriedades bem distintas. Por exemplo, um baixo teor de cálcio no CAT, como naqueles oriundos da ativação do metacaulim ou cinzas, propicia, como produto de reação, um gel composto por aluminatos e silicatos hidratados. Este gel pode ter uma estrutura similar àquela de polímeros orgânicos e por isto, estes aglutinantes são às vezes chamados de polímeros inorgânicos ou geopolímeros. Ao contrário, um alto teor de cálcio no CAT, como ocorre naqueles oriundos de escória de alto forno, propicia a formação do silicato de cálcio hidratado, com um moderado grau de substituição de $\mathrm{Al}$ e baixa relação $\mathrm{Ca} / \mathrm{Si}$, o C-(A)-S-H, que é amorfo para parcialmente cristalino [3].

Desta forma, os cimentos álcali-ativados (CAT's) podem envolver apenas o reuso de subprodutos da indústria, muitas vezes ainda sem destinação correta ou valorizada, e não exigem a calcinação da matériaprima, diminuindo assim a emissão de gases poluentes na atmosfera. Estima-se que no processo de fabricação do CAT, a redução da emissão de $\mathrm{CO}_{2}$ pode ser de $80 \%$, em relação ao CP [4]. Um significativo grupo de pesquisadores tem demonstrado excelentes propriedades mecânicas de cimentos álcali ativados $[5,6,7,8]$.

A utilização de escórias de alto forno para a produção de CAT's já vem sendo pesquisada desde os anos de $1940[9,10]$. Esse subproduto apresenta vantagem em sua aplicação devido a sua composição química semelhante à do cimento Portland. Além disso, devida à produção do ferro-gusa ser elevada, a escória é gerada em larga escala, o que torna necessário o seu consumo.

De acordo com PAL et al. [11], a reatividade da escória depende das suas propriedades, ou seja; fonte, composição química, finura, tipo de matéria-prima utilizada, método e taxa de resfriamento da mesma. Temse observado, entretanto, que grande parte das pesquisas em cimentos álcali ativados tem investigado mais o tipo de ativador do que as características da matéria-prima.

A finura é um fator condicionante de reatividade, uma vez que se sabe que maior a sua superfície específica, maior o contato com o ativador, que é o responsável pela ativação e reação inicial.

A química detalhada da ativação alcalina é ainda objeto de muito debate na literatura científica; pois para a confecção de cimentos álcali-ativados, a qualidade e a quantidade dos produtos de reação são determinados a partir da composição química e mineralógica da matéria-prima utilizada, da natureza do componente alcalino escolhido e das condições de aplicação [12]

Recentemente, BEN HAHA et al. [6, 7, 13] estudaram a ativação de escórias contendo diferentes composições químicas. O estudo mostrou que escórias com maiores quantidades de $\mathrm{MgO}$ propiciaram aumento no desenvolvimento da resistência à compressão e formação de hidrotalcita $\left(\mathrm{Mg}^{2+}{ }_{x} \mathrm{Al}^{3+}{ }_{y}(\mathrm{OH})^{-2}\right.$ $\left.{ }_{(x+y)}\left(\mathrm{CO}_{3}\right)^{2-}{ }_{y / 2} \mathrm{mH}_{2} \mathrm{O}\right)$, além de diminuição da porosidade na microestrutura. Já a quantidade mais elevada de $\mathrm{Al}_{2} \mathrm{O}_{3}$ na matéria-prima diminui a taxa de calor liberado na hidratação inicial da escória, mas não tem influência significativa na resistência final das argamassas, porém os autores relatam a maior incorporação des- 
te componente no composto CSH das pastas hidratadas.

O efeito da variabilidade física e química da escória de alto forno ainda não foi bem entendido, proporcionando forte impulso para investigação nesta área. Neste contexto, este artigo tem por finalidade contribuir no entendimento da influência das características das escórias de alto forno, finura e composição química, ativadas com hidróxido de sódio $(\mathrm{NaOH})$, no desempenho de cimentos álcali ativados.

\section{MATERIAIS E MÉTODOS}

\subsection{Materiais}

Foram utilizadas duas escórias granuladas de alto forno, uma proveniente de alto forno a carvão vegetal, ácida (A), e outra de alto forno a coque, básica (B). A composição química das escórias foi determinada pela análise semi quantitativa de fluorescência de raios-X, apresentada na Tabela 1. Pode-se observar que a escória A apresentar maiores teores de $\mathrm{Al}_{2} \mathrm{O}_{3}, \mathrm{SiO}_{2}$ e $\mathrm{MgO}$ e menor teor de $\mathrm{CaO}$.

A Figura 1 apresenta os difratogramas das escórias obtidos pela difração de raios-X. Observa-se que ambas podem ser consideradas como materiais amorfos devido ao fato de não apresentarem picos característicos e dessa forma uma ausência de um arranjo ordenado e periódico de átomos.

Tabela 1: Composição química (óxidos em \%) das escórias de alto forno.

\begin{tabular}{l|l|l}
\hline \multirow{2}{*}{ COMPONENTE } & ESCÓRIA A & ESCÓRIA B \\
\cline { 2 - 3 } & TEOR (\%) & TEOR (\%) \\
\hline $\mathrm{SiO}_{2}$ & 38,1 & 32,2 \\
\hline $\mathrm{CaO}$ & 37,0 & 49,5 \\
\hline $\mathrm{Al}_{2} \mathrm{O}_{3}$ & 13,9 & 8,2 \\
\hline $\mathrm{MgO}$ & 6,2 & 5,0 \\
\hline $\mathrm{Fe}_{2} \mathrm{O}_{3}$ & 1,3 & 0,8 \\
\hline $\mathrm{MnO}$ & 1,1 & 1,3 \\
\hline $\mathrm{K}_{2} \mathrm{O}$ & 0,9 & 0,5 \\
\hline $\mathrm{TiO}_{2}$ & 0,8 & 0,6 \\
\hline $\mathrm{Na}_{2} \mathrm{O}$ & 0,2 & 0,1 \\
\hline $\mathrm{SrO}^{\mathrm{SO}}$ & 0,1 & 0,2 \\
\hline $\mathrm{SO}_{3}$ & 0,1 & 1,4 \\
\hline
\end{tabular}

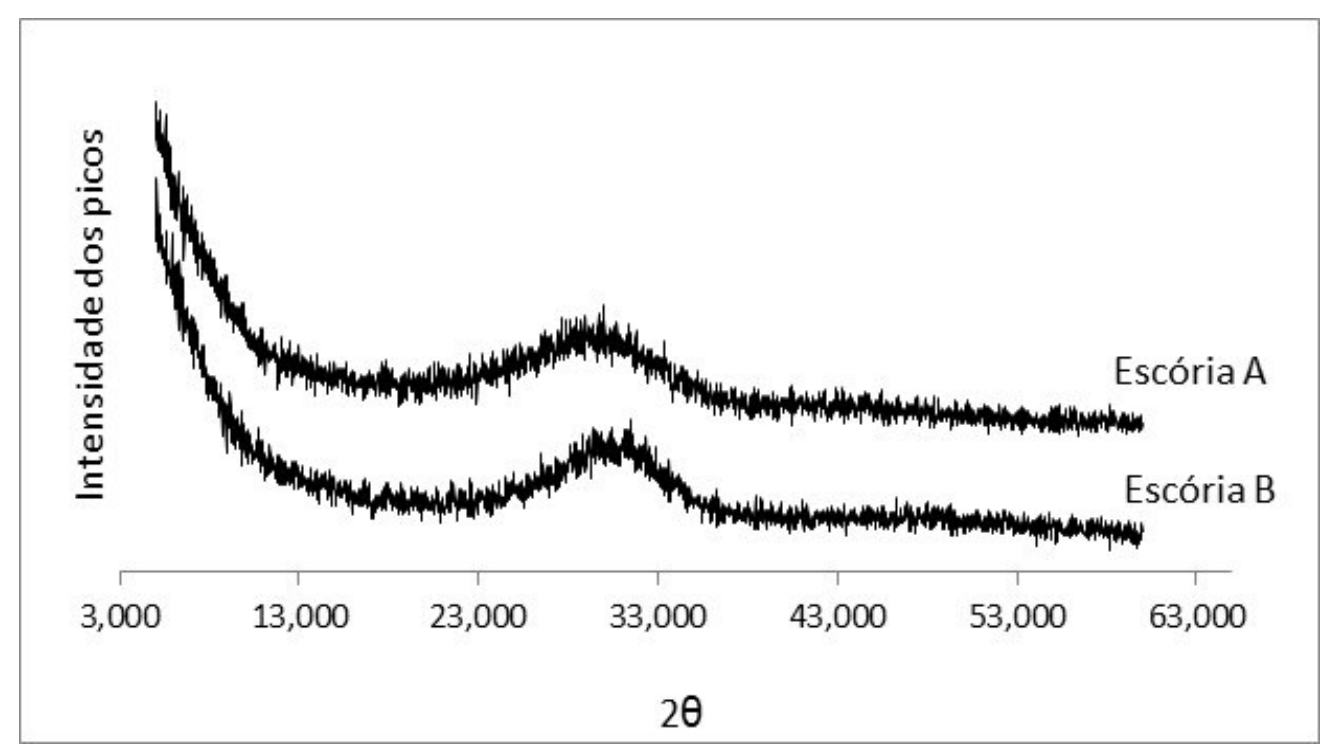

Figura 1: Difração de Raios-X. 
A preparação das escórias granuladas consistiu na secagem em estufa, por aproximadamente 24 horas em temperatura controlada de $105^{\circ} \mathrm{C}$ e, após foram trituradas em moinho de bolas. Para verificação da uniformidade do processo de moagem foi determinada a finura de cada escória pelo método de permeabilidade ao ar (Blaine), conforme Tabela 2. Os aspectos das escórias granuladas antes e após a trituração pode ser observado na Figura 2.
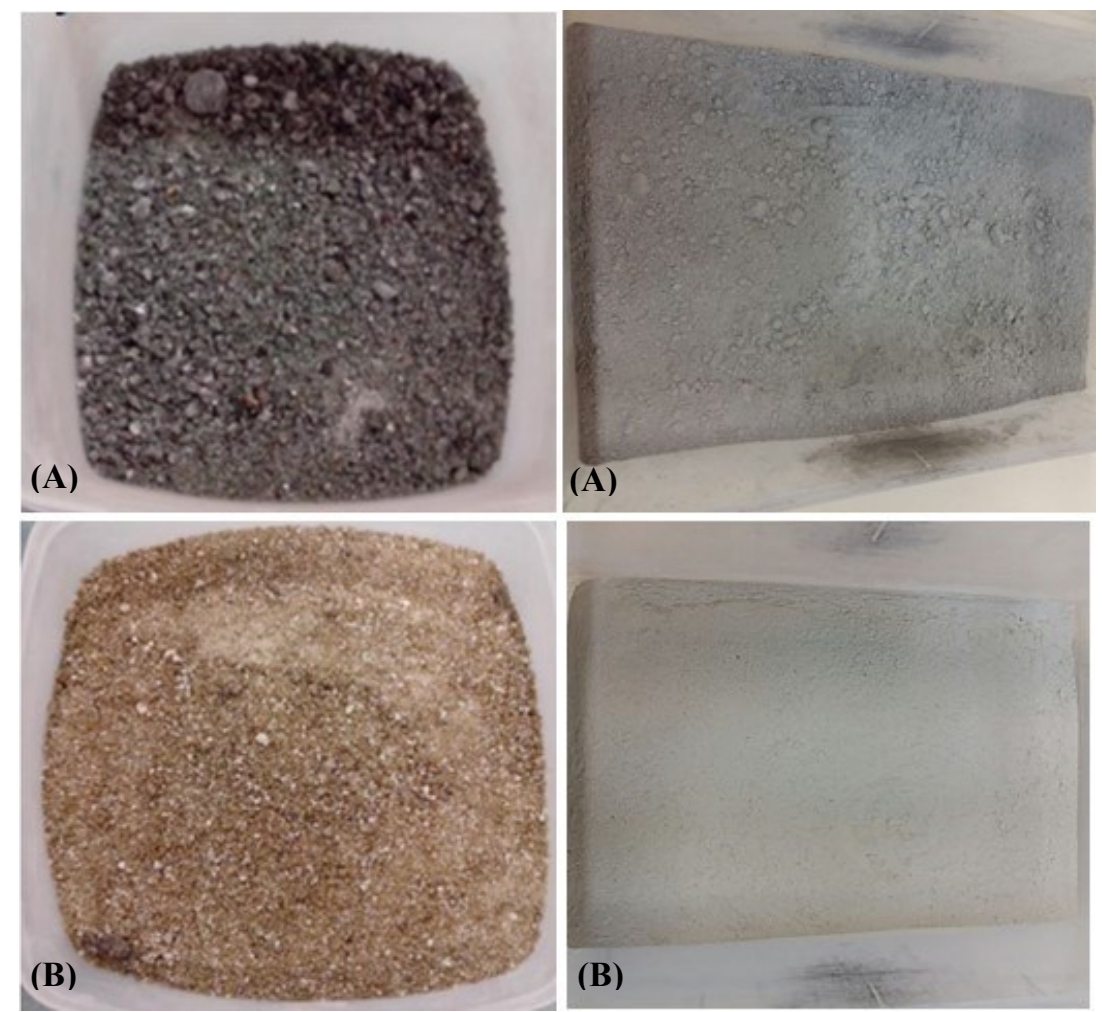

Figura 2: Aspectos das escórias trituradas, escória (A) e escória (B).

Tabela 2: Caracterização física das escórias: Superfície específica obtida pelo método Blaine.

\begin{tabular}{l|l}
\hline ESCÓRIA & SUPERFÍCIE ESPECÍFICA $\left(\mathbf{c m}^{2} \mathbf{l g}\right)$ \\
\hline A (1h) & 3354 \\
\hline A (2h) & 5352 \\
\hline B (2h) & 4410 \\
\hline
\end{tabular}

Pode-se observar que mesmo padronizando o tempo de moagem para as escórias A e B, a primeira apresentou maior superfície específica, de $5352 \mathrm{~cm}^{2} / \mathrm{g}$. Entretanto, o tempo de $1 \mathrm{~h}$ de moagem, também para a escória $\mathrm{A}$, permitiu obter uma finura inferior àquela apresentada pela escória $\mathrm{B}$, condição necessária para avaliar a influência, tanto da finura quanto da composição química, no desempenho dos CAT's.

\subsection{Métodos}

A elaboração do cimento álcali ativado consistiu na ativação das escórias usando o $\mathrm{NaOH}$, em teor de $5 \%$ em relação à massa da escória para pastas e argamassas, baseado em estudo recente [15].

Para avaliar a influência da composição química das escórias o tempo de moagem foi padronizado, para ambas as escórias (A e B), em 2 h. Para avaliar a influência da finura, apenas a escória A foi tritura por um tempo menor, de 1 hora, visando reduzir sua superfície específica.

Foram elaboradas pastas e argamassas para a realização dos ensaios. As pastas foram confeccionadas com relação água/escória (a/e) de 0,4 para as análises de calorimetria e de microestrutura. Para o ensaio de resistência mecânica, realizado em argamassa, o traço utilizado foi 1:2,75:0,485 (escória : agregado : água, em massa), de acordo com a ASTM C 348-02 [16], e a areia utilizada foi a padrão do IPT. Os parâmetros dos 
métodos utilizados estão especificados nos próximos itens.

\subsection{Resistência Mecânica}

Para o ensaio de resistência mecânica, após moldagem, os corpos-de-prova foram curados em câmara úmida (temperatura de $23^{\circ} \mathrm{C}$ e umidade relativa superior a $95 \% \mathrm{RH}$ ) até a idade de 7 e 28 dias. A resistência à compressão das argamassas foi medida em triplicada ( 3 corpos de prova para cada composição e idade) e os resultados analisados estatisticamente, de acordo com o teste paramétrico de análise de variância (ANOVA).

\subsection{Calor de hidratação}

Para a realização do ensaio, as pastas foram inseridas no calorímetro, marca Calmetrix, modelo I-Cal 2000 HPC, e foram monitoradas por 7 dias, em temperatura de $23^{\circ} \mathrm{C}$. A partir das curvas obtidas,e de acordo com o método apresentado por ANTUNES DA SILVA [17], (Figura 3), foram determinados:

- Duração do período de indução;

- Final do período de indução;

- Fluxo máximo de calor no pico principal e

- Tempo para atingir fluxo máximo (fim da pega).

O final do período de indução (correspondente ao início da pega) pode ser obtido a partir da intersecção das retas do trecho horizontal e da reta de regressão linear (tangente) do período de aceleração. O fluxo máximo de calor ou taxa máxima de calor liberado pode ser obtido por leitura direta nas curvas.

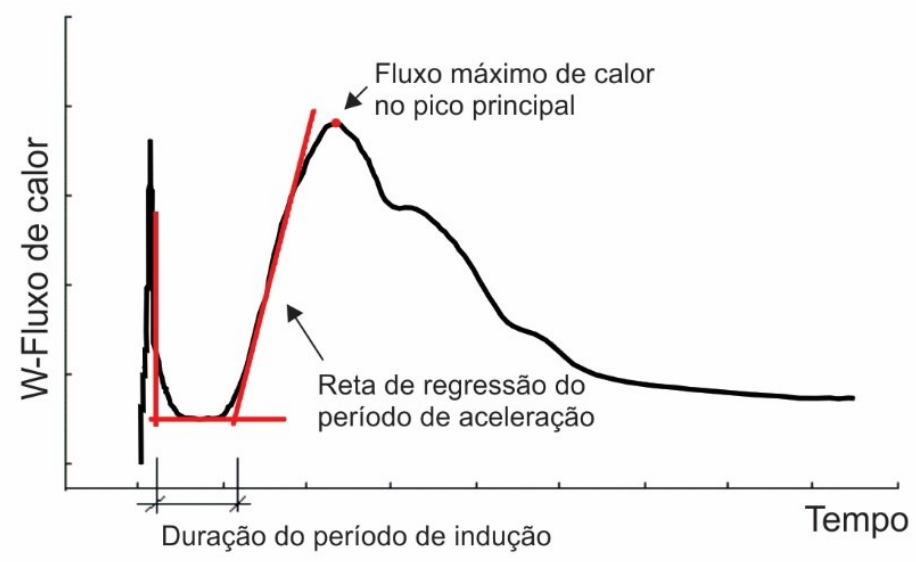

Figura 3: Representação esquemática de curva de fluxo de calor de hidratação e critérios de determinação das variáveis.

\subsection{Microestrutura}

Para investigação da microestrutura, foram confeccionadas pastas apenas para escórias (A e B) trituradas por 2 horas. Estas pastas foram submetidas às técnicas de Difração de Raios-X (DRX) e Calorimetria exploratória diferencial (DSC) na idade de 28 dias.

A interrupção da hidratação consistiu em fraturar as amostras e colocá-las submersas em acetona P.A, onde ficaram em repouso por duas horas. Posteriormente, o excesso de acetona foi retirado e as amostras colocadas num filtro de buchner acoplado à bomba a vácuo para sucção da acetona restante. Após secas, para completar o processo, as amostras foram deixadas em temperatura controlada (aproximadamente $40^{\circ} \mathrm{C}$ ) por 24 horas e então trituradas em granulometria inferior a $150 \mu \mathrm{m}$.

\subsection{Difração de Raios-X (DRX)}

Para a realização do ensaio, foi utilizado o equipamento utilizado foi da marca Panalytical, modelo EMPYREAN, o qual utiliza um tubo de radiação $\mathrm{Cu}-\mathrm{K} \alpha,(40 \mathrm{kV}, 25 \mathrm{~mA})$. As amostras foram analisadas de acordo com as seguintes condições:

- Comprimento de onda de 1,54 $\breve{A}$;

- Ângulos de varredura de $5^{\circ}-70^{\circ}(2 \theta)$;

- Passo de $0,02^{\circ}$, sendo as intensidades registradas por $10 \mathrm{~s}$ em cada passo; 


\subsection{Calorimetria exploratória diferencial (DSC)}

Para análise de calorimetria exploratória diferencial (DSC), foi utilizado o equipamento da marca TA Instruments, modelo DSC Q20. Para esta análise foram utilizadas as seguintes condições:

- Faixa de aquecimento de $30{ }^{\circ} \mathrm{C}$ a $600{ }^{\circ} \mathrm{C}$;

- Taxa de aquecimento de $10^{\circ} \mathrm{C} \mathrm{min}^{-1}$;

- Atmosfera inerte: ar sintético;

- Fluxo de $100 \mathrm{~mL} \mathrm{~min}^{-1}$;

- Porta amostra de alumínio hermeticamente fechado com um furo na tampa.

\section{RESULTADOS}

\subsection{Resistência Mecânica}

A Figura 4 apresenta os resultados de resistência mecânica apresentados pelos CAT's, formulados com a escória A e B, trituradas por $2 \mathrm{~h}$, e escória A triturada por $1 \mathrm{~h}$, com superfície específica de 5352, 4410 e $3354 \mathrm{~cm}^{2} / \mathrm{g}$, respectivamente.

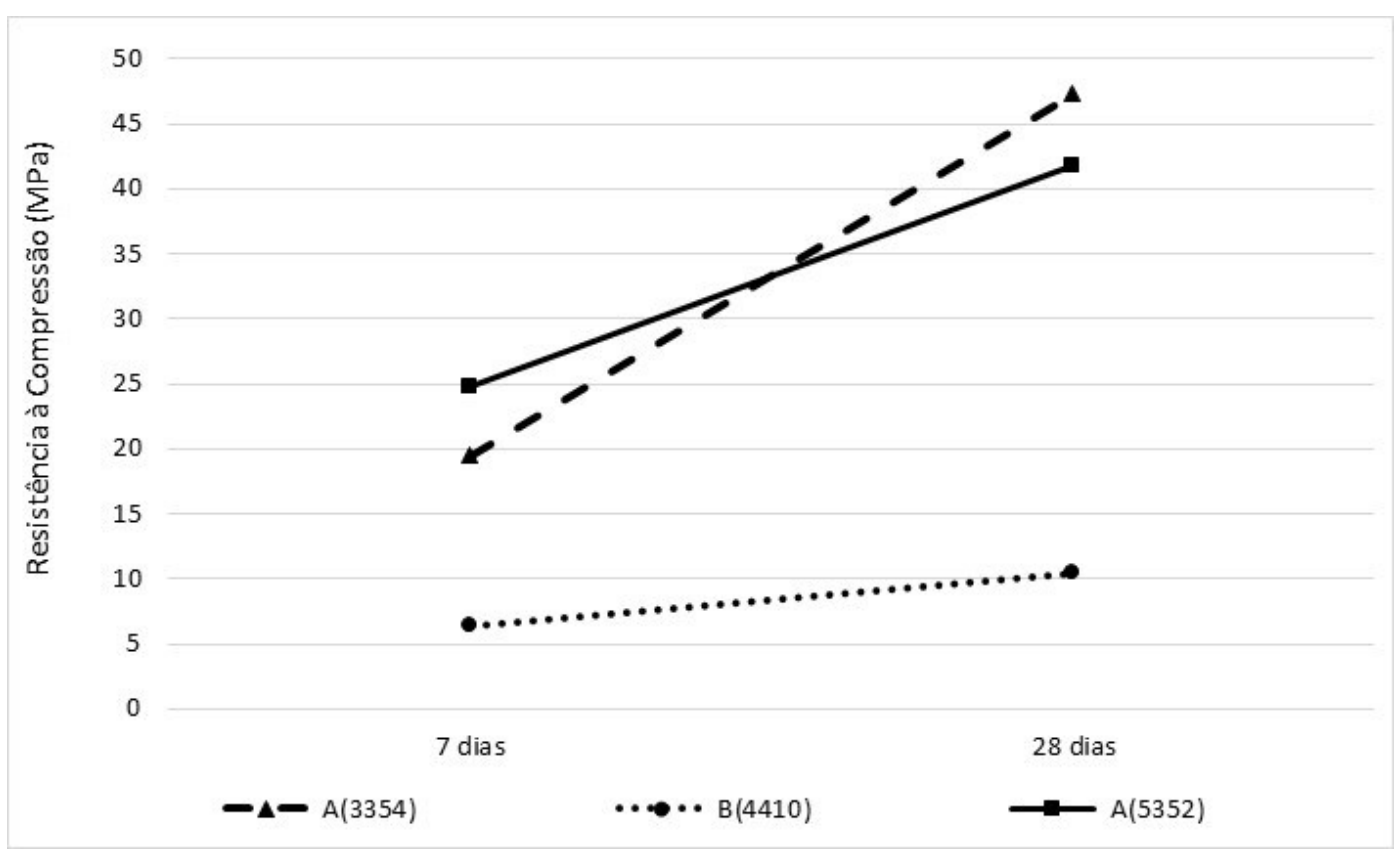

Figura 4: Resistência à compressão dos corpos de prova das escórias $\mathrm{A}(3354), \mathrm{A}(5352)$ e $\mathrm{B}(4410)$ aos 7 e 28 dias.

A partir dos resultados obtidos aos 7 e 28 dias, em relação à finura (avaliada na escória A), se observa que esta é pouco significativa. Os valores aos 7 dias são muito próximos, a resistência cai apenas $5 \mathrm{MPa}$, sendo que aos 28 dias a resistência mecânica atinge valores superiores para escória com tempo de moagem menor. $\mathrm{O}$ desvio padrão obtido para estas amostras variou na faixa de 0,4 a 3,1 MPa. Já, em relação à influência da composição química (escória $\mathrm{A}$ e B), o desenvolvimento da resistência à compressão apresentado pela argamassa com escória B é bastante inferior, atingindo valores de apenas $10 \mathrm{MPa}$ aos 28 dias, sendo que o desvio padrão dos resultados obtidos variou entre 0,2 e $0,4 \mathrm{MPa}$. Para ambas as escórias, o valor máximo do coeficiente de variação obtido foi $9 \%$.

A análise ANOVA com confiança de $95 \%$ foi realizada para comparar estatisticamente a influência dos fatores finura e idade nas amostras com escória A e B, conforme Tabela 3. O resultado obtido confirma a significância desse fator perante o desenvolvimento da resistência à compressão. Porém quando a análise é realizada apenas para a escória $\mathrm{A}$, a finura não se mostra significativa, como pode ser observado na Tabela 4 . 
Tabela 3: Análise ANOVA para a escória A e B, com diferentes finuras.

\begin{tabular}{l|l|l|l|l|l|l|l}
\hline FONTE DE VARIAÇÃO & SQ & CONTRIBUIÇÃO (\%) & GLD & MQ & TESTE F & F TABELADO & SIGNIFICÂNCIA \\
\hline Finura da escória (A) & 2487,9 & 60,20 & 2 & 1243,9 & 443,7 & 3,9 & Significativo \\
\hline Idades (B) & 1191,2 & 28,80 & 1 & 1191,2 & 424,9 & 4,8 & Significativo \\
\hline AB & 422,2 & 10,20 & 2 & 211,1 & 75,3 & 3,9 & Significativo \\
\hline Erro & 33,6 & 0,80 & 12 & 2,8 & & & \\
\hline Total & 4134,9 & 100,00 & 17 & & & & \\
\hline
\end{tabular}

Tabela 4: Análise ANOVA para a escória A, com diferentes finuras.

\begin{tabular}{l|l|l|l|l|l|l|l}
\hline FONTE DE VARIAÇÃO & SQ & \% CONTRIBUIÇÃO & GLD & MQ & TESTE F & F TABELADO & SIGNIFICÂNCIA \\
\hline Finura (A) & 0,0 & 0,0 & 1 & 0,01 & 0,00 & 5,3 & Não significativo \\
\hline Idades (B) & 1501,0 & 92,7 & 1 & 1501,0 & 361,5 & 5,3 & Significativo \\
\hline AB & 87,5 & 5,4 & 1 & 87,5 & 21,1 & 5,3 & Significativo \\
\hline Erro & 33,2 & 2,0 & 8 & 4,2 & & & \\
\hline Total & 1621,8 & 100,0 & 11 & & & & \\
\hline
\end{tabular}

\subsection{Calorimetria de condução isotérmica}

O ensaio de calorimetria de condução isotérmica também foi realizado a fím de verificar se a finura da matéria-prima altera o tempo de pega e o calor de hidratação das pastas. Na Figura 5 tem-se as curvas de calor liberado e calor total acumulado para todas as pastas. Os resultados numéricos estão contidos na Tabela 5.

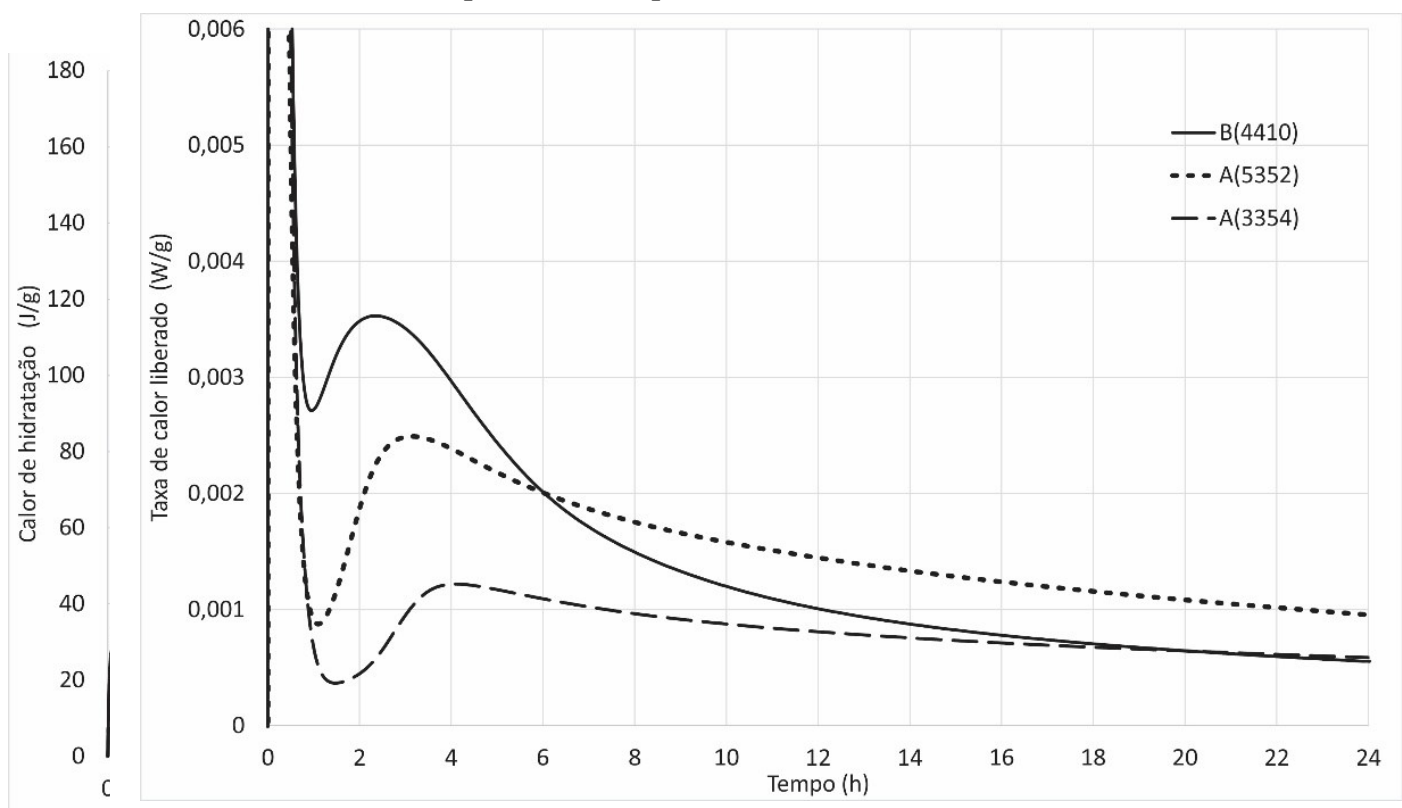

Figura 5: Curvas de calorimetria de condução das pastas de escória A(5352), A(3354) e B(4410) ativadas com 5\% de $\mathrm{NaOH}$.

Com relação às curvas obtidas para a taxa de calor liberado, o primeiro pico se refere à dissolução inicial da escória. A taxa de calor liberado é alta devido, também, à própria dissolução do $\mathrm{NaOH}$, que libera grande quantidade de calor, elevando a temperatura da mistura inicial. O segundo período, entre o pico inicial e o segundo pico, é chamado de período de indução, o qual apresenta baixo calor liberado e uma baixa reatividade do material. Já o segundo pico, considerado o principal pico ocorrido, é um período de enorme reatividade, pois ocorre grande precipitação dos produtos hidratados e a formação dos principais compostos; no caso do cimento álcali ativado, o CSH e a hidrotalcita. Após esta etapa o material entra no estágio final da hidratação, com baixa reatividade, porém com ganho de resistência. 
Tabela 5: Dados de tempo de início e fim de pega, duração do período de indução e pico máximo dos CAT’s com escória $\mathrm{A}$ (diferentes finuras) e B.

\begin{tabular}{l|l|l|l|l}
\hline & \multirow{2}{*}{$\begin{array}{l}\text { DURAÇÃO DO PERÍODO } \\
\text { DE INDUÇÃO } \\
\text { (HORAS:MINUTOS) }\end{array}$} & $\begin{array}{l}\text { FIM DO PERÍODO DE } \\
\text { INDUÇÃO } \\
\text { (INÍCIO DE PEGA) } \\
\text { (HORAS:MINUTOS) }\end{array}$ & $\begin{array}{l}\text { PLUXO MÁXIMO } \\
\text { (KW/G) } \\
\text { (X10-6) }\end{array}$ & $\begin{array}{l}\text { TEMPO PARA ATINGIR } \\
\text { FLUXO MÁXIMO } \\
\text { (FIM DE PEGA) } \\
\text { (HORAS:MINUTOS) }\end{array}$ \\
\hline $\mathrm{A}(3354)$ & $01: 12$ & $02: 06$ & 1,22 & $04: 06$ \\
\hline $\mathrm{A}(5352)$ & $00: 30$ & $01: 18$ & 2,49 & $03: 06$ \\
\hline $\mathrm{B}(4410)$ & $00: 11$ & $01: 00$ & 3,53 & $02: 21$ \\
\hline
\end{tabular}

Observa-se que a finura da matéria-prima altera o calor de hidratação da pasta, porém a pasta com escória A menos fina (3354) continua a seguir o mesmo padrão de hidratação da pasta com escória A mais fina (5352) seu pico inicial é menor, seu início de pega tardio (2 horas e 6 minutos) e a liberação de calor inferior. Já comparando com a pasta com escória B(4410), esta última apresenta um pico maior de hidratação, com início de pega precoce as demais (1 hora), e uma liberação de calor inicial superior, o qual diminui ao longo do tempo se aproximando da pasta com escória A(3354) já nas primeiras 24 horas.

\subsection{Difração de Raios-X}

A Figura 6 representa os difratogramas das pastas de escória A e B ativadas com 5\% de NaOH, aos 28 dias. Em ambas as escórias, o pico de CSH pode ser identificado em torno de $29^{\circ}-30^{\circ} 2 \theta$, os quais também foram encontrados por BEN HAHA et al. [6, 7, 13] (PDF 00-033-0306 e PDF 00-034-0002).

Apesar do pico de CSH ser destacado na escória A, os difratogramas obtidos para o CAT com escória $\mathrm{B}$ têm picos mais definidos e regulares. Além disso, a fase hidrotalcita que aparece em $11^{\circ}$ e $23^{\circ} 2 \theta$ (PDF 01089-0460), não foi observada no difratograma do CAT com escória A na idade de 28 dias, talvez pelo fato de a quantidade ser pequena e não detectável pela técnica.

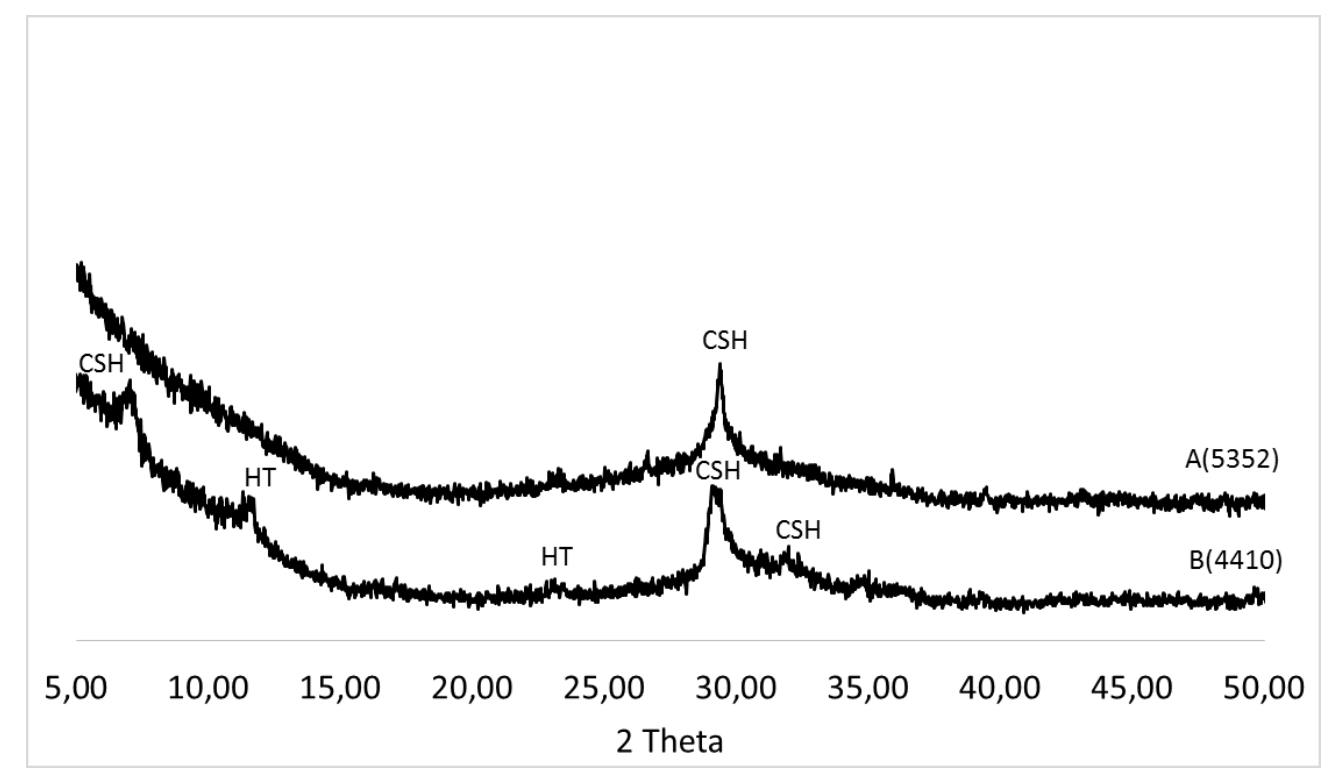

Figura 6: Difratograma das pastas com escória A(5352) e B(4410), aos 28 dias. CSH - Silicato de cálcio hidratado, HT Hidrotalcita.

\subsection{Calorimetria exploratória diferencial}

A partir das análises térmicas (DSC), foi possível identificar os compostos hidratados de forma a confirmar os picos observados na análise de DRX.

Na Figura 7 podem ser observadas as análises obtidas para as pastas de escória A e B ativadas com $5 \%$ de $\mathrm{NaOH}$ aos 28 dias. 
Para ambas os CAT's foram identificados os picos de $\mathrm{CSH}$ (entre $50^{\circ}$ e $200^{\circ} \mathrm{C}$ ) e a fase hidrotalcita (pico máximo entre $300^{\circ}$ e $400^{\circ} \mathrm{C}$ ). Foi observado um pico também após a temperatura de $500^{\circ} \mathrm{C}$ na pasta com escória A o que poderia indicar fases de carbonato de cálcio $\left(\mathrm{CaCO}_{3}\right)$. Na pasta com escória $\mathrm{B}$ a fase hidrotalcita se mostra mais evidente, como pode ser observado também na análise de DRX.

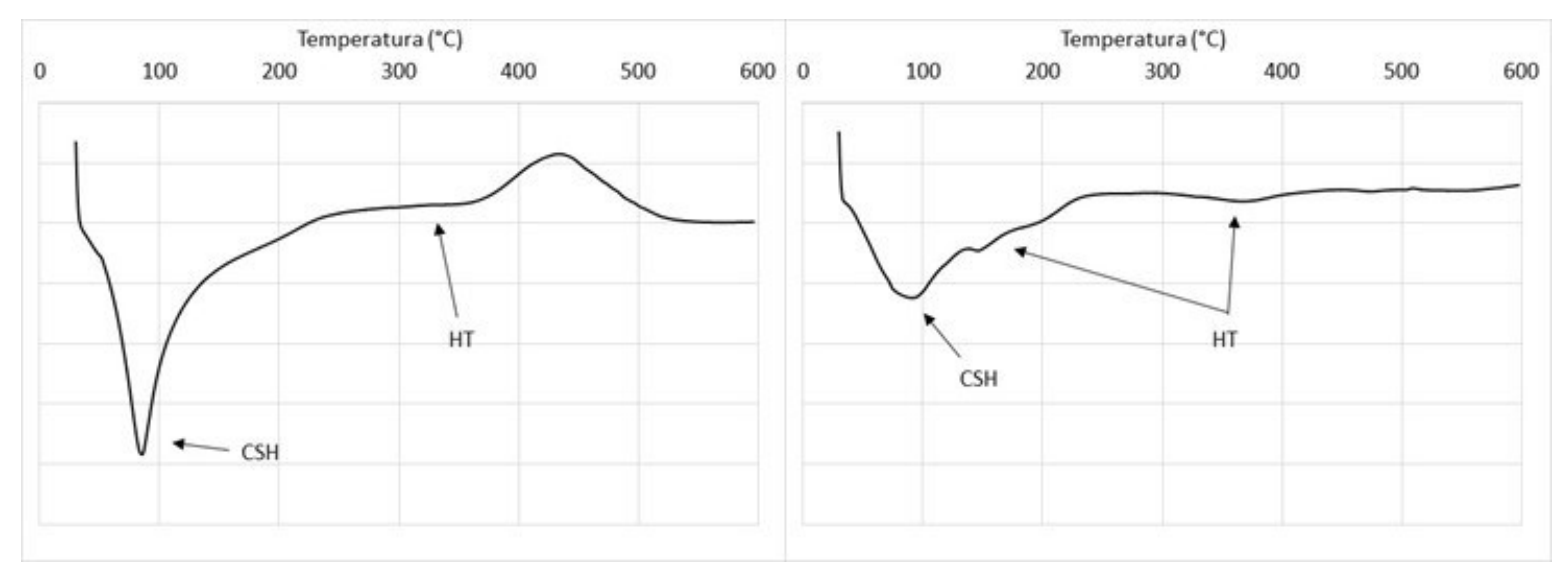

Figura 7: Calorimetria exploratória diferencial das pastas com escoria A e B, respectivamente, ativadas com 5\% de $\mathrm{NaOH}, 28$ dias. CSH - Silicato de cálcio hidratado, HT - Hidrotalcita.

\section{DISCUSSÃO}

Para o ensaio de resistência à compressão, nota-se que a composição química da matéria-prima tem fator relevante no desenvolvimento do cimento álcali ativado, e que a finura exerce pequena influência. Os valores de resistência à compressão apresentados pelas argamassas com a escória $\mathrm{A}$ foram superiores àqueles apresentados pela escória $\mathrm{B}$. $\mathrm{O}$ teor de $\mathrm{MgO}$ são superiores para a escória $\mathrm{A}$, o que pode ter contribuído para desenvolvimento da resistência mecânica e microestrutura, conforme cita também os autores BEN HAHA et al. $[7,13]$ em seus trabalhos recentes.

Em relação à finura, investigada na escória $\mathrm{A}$, aquela com menor tempo de moagem, liberou menor calor de hidratação, desenvolvendo uma resistência à compressão menor aos 7 dias, porém, aos 28 dias, a finura não teve mais influência na resistência mecânica. Em relação à composição química, se comparada com a escória B, o pico de hidratação também foi menor, porém a resistência foi maior; indicando mais uma vez que a composição química da matéria-prima tem maior influência no desempenho do CAT.

A partir dos ensaios para avaliação dos compostos formados e microestrutura (DRX e DSC) nota-se que as quantidades destes elementos podem ser fatores condicionantes para formação dos compostos. Segundo SCHNEIDER et al. [18], o CSH formado a partir da hidratação de escórias é geralmente rico em alumínio e, segundo BEN HAHA et al. [7] a quantidade de $\mathrm{Al}_{2} \mathrm{O}_{3}$ pode aumentar a incorporação de $\mathrm{Al}$ no $\mathrm{CSH}$, tornando o sistema mais amorfo. Dessa forma, a quantidade da fase hidrotalcita pode ser diminuída, uma vez que esta depende dos componentes $\mathrm{MgO}$ e $\mathrm{Al}_{2} \mathrm{O}_{3}$ para sua formação, fato que ocorre com as pastas de escória A.

Porém, os valores de resistência à compressão obtidos para as argamassas confeccionadas com escória B foram inferiores aos obtidos para as argamassas com escória A, o que indica mais uma vez que as fases formadas podem ser bastante amorfas e mais difíceis de caracterizar neste sistema o que pode estar ligada a quantidade de $\mathrm{Al}_{2} \mathrm{O}_{3}$, a qual é maior na escória $\mathrm{A}$, conforme afirmam CHEN et al. [19].

Segundo TAYLOR [20] as composições de maior resistência mecânica apresentam menor cristalinidade nas análises de DRX, com picos mais alargados e menor quantidade de picos do CSH. Isto pode ser observado nas argamassas com escória $\mathrm{A}$, pois os valores de resistência à compressão destas foram superiores, sendo que seu difratograma mostrou apenas um pico principal e uma estrutura mais amorfa.

\section{CONCLUSÕES}

Os resultados mostraram a performance do cimento álcali ativado perante o uso de duas escórias com composições químicas e finuras diferentes, ativadas com $5 \%$ de $\mathrm{NaOH}$. A partir disso, foi possível concluir que:

- Quando comparados os resultados de resistência mecânica das argamassas obtidas a partir de escórias com diferentes finuras e composições químicas, ficou claro que a última é a principal responsável pelo melhor desempenho do CAT; a diferença entre os valores de resistência mecânica é significativa apenas quando 
comparadas a escória A com a escória B;

- A finura da matéria-prima proporciona uma maior reatividade do material, a qual é significativa apenas nas idades iniciais, não afetando significativamente a resistência à compressão aos 28 dias. A pasta com escória A, com menor tempo de moagem, liberou menor calor de hidratação e apresentou uma menor resistência à compressão aos 7 dias.

- O aumento de resistência que ocorre na idade de 28 dias com o CAT de escória A mais fina pode ter sido devido ao menor calor de hidratação liberado, proporcionando um desenvolvimento de uma microestrutura menos porosa.

- Quando comparada com a escória B, o calor liberado e pico de hidratação desenvolvido pela CAT com escória $\mathrm{A}$, com menor tempo de moagem da matéria-prima, também foram menores, porém a resistência foi maior; indicando mais uma vez que a composição química da matéria-prima tem influência mais significativa que a finura no desempenho do cimento álcali ativado.

- Quanto às fases formadas e observadas nas análises de DRX e DSC, notou-se que o sistema no CAT com escória A é mais amorfo, e uma hipótese levantada, de acordo com resultados obtidos na literatura, é que escórias com maiores teores de $\mathrm{Al}_{2} \mathrm{O}_{3}$ podem desenvolver o composto $\mathrm{CSH}$ com maior incorporação de $\mathrm{Al}$, podendo assim diminuir a formação da fase hidrotalcita.

\section{AGRADECIMENTOS}

Os autores agradecem ao CNPq pelo apoio financeiro e à bolsa de iniciação científica, e à Capes, pela bolsa de mestrado.

\section{BIBLIOGRAFIA}

[1] MINISTÉRIO DO DESENVOLVIMENTO, IDÚSTRIA E COMÉRCIO EXTERIOR (MDIC). Nota Técnica Plano Indústria Subsetor Cimento, http://www.mdic.gov.br/arquivos/dwnl_1352304842.pdf. Acessado em janeiro de 2016.

[2] AITCIN, P. C., MINDESS, S. Sustainability of Concrete, 1 ed. USA e Canada, Spon Press, 2011.

[3] JUENGER, M. C. G., WINNEFELD, F., PROVIS, J. L., et al. "Advances in alternative cementitious binders", Cement and Concrete Research, v. 41, 1232-1243 p., 2011.

[4] DUXSON, P., PROVIS, J. L., LUKEY, G. C., et al., "The role of inorganic polymer technology in the development of 'green concrete", Cement and Concrete Research, v. 37, 1590-1597 p., 2007.

[5] BUCHWALD A. H., KAPS, H. C. "Alkali-activated metakaolin-slag blends -performance and structure in dependence of their composition. Advances in geopolymer Science \& Technology", Journal of Materials Science, v. 42, ed. 9, 3024-3032 p., 2007.

[6] BEN HAHA, M., LE SAOUT, G., WINNEFELD, F., et al., "Influence of activator type on hydration kinetics, hydrate assemblage and microstructural development of alkali activated blast-furnace slags", $\mathrm{Ce}$ ment and Concrete Research, v. 41, ed. 3, 301-310 p., 2011.

[7] BEN HAHA, M., LOTHENBACH, B., LE SAOUT, G., et al., "Influence of slag chemistry on the hydration of alkali-activated blast-furnace slag - Part II: Effect of $\mathrm{Al}_{2} \mathrm{O}_{3}$ ", Cement and Concrete Research, v. 42, ed. 1, 74-83 p., 2012.

[8] PUERTAS, F., PALACiOS, M., GUTIÉRREZ, R. "Morteros de Escoria Activada Alcalinamente. Propiedades y Durabilidad", In: $2^{\circ}$ Congresso Nacional de Argamassas de Construção, Lisboa, 2007.

[9] LI, C., SUN, H., LI, L. "A review: The comparison between alkali-activated slag $(\mathrm{Si}+\mathrm{Ca})$ and metakaolin ( $\mathrm{Si}+\mathrm{Al})$ cements", Cement and Concrete Research, v. 40, ed. 9, 1341-1349 p., 2010.

[10] SHI, C., FERNÁNDEZ-JIMÉNEZ, A., PALOMO, A. "New cements for the 21st century: The pursuit of an alternative to Portland cement", Cement and Concrete Research, v. 41, ed. 7, 750-763 p., 2011.

[11] PAL, S. C, MUKHERJEE, A., PATHAK, S. R. "Investigation of hydraulic activity of ground granulated blast furnace slag in concrete", Cement and Concrete Research, v. 33, ed. 9, pp. 1481-1486, 2003.

[12] ALONSO, S., PALOMO, A. "Alkaline activation of metakaolin and calcium hydroxide mixtures: influence of temperature, activator concentration and solids ratio", Materials Letters, v. 47, pp. 55-62, 2001.

[13] BEN HAHA, M., LOTHENBACH, B., LE SAOUT, G., et al., "Influence of slag chemistry on the hydration of alkali-activated blast-furnace slag - part I: effect of MgO", Cement and Concrete Research, v. 41, ed. 9, 955-963 p., 2011.

[14] PROVIS, J., DEVENTER, J. V. “Alkali activated materials: State-of-the-Art Report”, RILEM TC 224- 
$A A M$, v. 13. Springer Netherlands, 2014.

[15] LANGARO, E. Cimento álcali ativado a partir da valorização da escória de alto forno a carvão vegetal, Dissertação de Mestrado, PPGEC/UTFPR, Curitiba, PR, Brasil, 2016.

[16] AMERICAN SOCIETY FOR TESTING AND MATERIALS. ASTM C348/2: Standard Test Method for Flexural Strength of Hydraulic-Cement Mortars. Estados Unidos, 2002.

[17] ANTUNES DA SILVA, D. Efeitos dos polimeros HEC e EVA na microestrutura de pastas de cimento Portland, Tese de D.Sc., PPGEM/UFSC, Florianópolis, SC, Brasil, 2001.

[18] SCHNEIDER, J., CINCOTTO, M. A., PANEPUCCI, H. "29Si and 27Al high resolution NMR characterization of calcium silicate hydrate phases in activated blast-furnace slag pastes", Cement and Concrete Research, v. 31, ed. 7, pp. 993-1001, 2001

[19] CHEN, W., BROUWERS, H. J. H. "The hydration of slag, part 1: reaction models for alkali-activated slag”, Journal of Materials Science, v.42, ed. 2, 428-443 p., 2007.

[20] TAYLOR, H. F. W. Cement Chemestry, 2 ed, Thomas Telford, 1997. 